\title{
A Molecular Dynamics Evaluation of the Effect of Dopant Addition on Grain Boundary Diffusion in Tin: Implication for Whisker Growth
}

\author{
S. Banerjee ${ }^{1 *}$, I. Dutta ${ }^{1}$ and B. S. Majumdar ${ }^{2}$ \\ ${ }^{1}$ School of Mechanical and Materials Engineering \\ Washington State University \\ Pullman, WA 99164-2920 \\ ${ }^{2}$ Materials and Metallurgical Engineering Department \\ New Mexico Tech \\ Socorro, NM87801, U.S.A
}

\begin{abstract}
$\underline{\text { Abstract }}$
Addition of lead dopant has been known to be an effective way of mitigating whisker growth in tin. However, the toxic nature of lead has necessitated a search for alternative dopant species. Recent investigations have indicated that indium can be an effective agent in reducing whisker growth. In an effort to investigate if reduction in diffusivity of tin atoms near grain boundaries in presence of dopant atoms is the underlying mechanism that causes reduced whisker growth, we employed molecular dynamics simulations to model tin grain boundaries with lead and indium dopants. We simulated pure tin grain boundary as well as grain boundaries with $4 \%$ dopants by mole fraction. Our results indicate that the dopant atoms segregate near the grain boundary and forms clusters, which in turn leads to reduced diffusivity of tin atoms by up to a factor of three. Since such reduction in diffusivity alone cannot reduce whisker growth by several orders of magnitude, we conclude that other mechanisms might play a more dominant role in mitigating tin whisker growth.
\end{abstract}

Keywords: Tin whisker; Molecular dynamics; Diffusion coefficient; Indium; Grain boundaries.

\footnotetext{
* Corresponding Author, Tel: +1 509 3350294, E-mail: soumik.banerjee@wsu.edu
} 


\section{INTRODUCTION}

In electronic packages, copper lead-frames are often electroplated with 5-20 $\mu \mathrm{m}$ thick tin (Sn) or a Sn-rich alloy to reduce oxidation and serve as a wetting-enhancer during subsequent soldering for lead $(\mathrm{Pb})$ attachment. Frequently, Sn whiskers, which may be hundreds of micrometers long, extrude from the electroplated surface during storage, causing electrical shorts between neighboring circuitry [1-3]. Whiskers have been observed in various systems (including Sn on $\mathrm{Cu}, \mathrm{Zn}$ on steel and $\mathrm{Al}$ on $\mathrm{Si}$ ) since the 1950s [3-22]. A number of reasons for whisker formation have been suggested, but there is now a consensus that 3 key conditions have to be satisfied for whiskers growth $[5,12,13,18,19,23,24]$. These are: (1) a mechanism to continually generate in-plane compressive stresses within the coating to provide the driving force for whisker growth, such as continuous formation of an interfacial reaction product (e.g., $\mathrm{Cu}_{6} \mathrm{Sn}_{5}$ for $\mathrm{Sn}$ coatings on $\mathrm{Cu}$ ), (2) a tenacious surface oxide layer which limits surface vacancy sources, thereby precluding stress-relief via diffusional processes, and (3) rapid grain boundary selfdiffusion of Sn to transport matter from the plating-interior to the growing whisker. Indeed, the presence of vertical columnar grain boundaries has been suggested to provide a rapid path for feeding whiskers [20], although by itself, this mechanism is not consistent with the continuing presence of in-plane compressive stress.

It has been known since the 1960s that the addition of 1-3 percent of $\mathrm{Pb}$ to the Sn plating leads to complete mitigation of whiskering [5]), and until recently, doping with $\mathrm{Pb}$ has been the primary approach for whisker mitigation in Sn. However, the recent regulatory ban on $\mathrm{Pb}$ in electronics has led to the urgency in developing alternative approaches for Sn whisker mitigation. These have comprised including some porosity in Sn platings [14], depositing a Ni inter-layer between the Cu substrate and Sn, and the use of conformal over-coats on Sn [23, 24]. 
However, none of these approaches has proved to be as effective or versatile in reducing whisker growth as doping with $\mathrm{Pb}$.

Recently, the addition of 5 to 10 percent indium (In) has been shown to completely prevent the growth of long whiskers (aspect ratio $>5$ ) from electroplated Sn coatings $[25,26]$ in samples aged at room temperature up to 1000 hours, proffering In dopants as a suitable alternative to $\mathrm{Pb}$. In this work, In was chosen as a dopant primarily because: (a) its atomic number is close to that of Sn (49 for In, 50 for Sn), minimizing the likelihood of chemical interaction; (b) In has moderate solubility in Sn (around 4 wt. \% at room temperature), which reduces the chance of precipitation of In within the Sn grains, and (c) like Pb, its atomic radius is larger than that of Sn

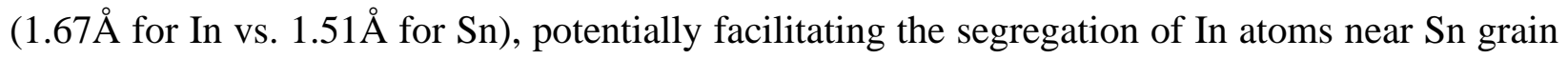
boundaries, and thereby slowing grain boundary self-diffusion of Sn to feed whisker growth. Although the need for a stress gradient as the driving force for Sn-whisker growth has been widely studied [12, 19, 21], and Cu-Sn intermetallic formation is well-known as the mechanism for continuously regenerating the stress to compensate for diffusionally driven relaxation [16], the root reason why alloy addition may alter the stress-state or whisker growth is unclear. Indeed, despite the clear evidence that $\mathrm{Pb}$ dramatically reduces whisker growth, as does In, there has been no reported study on the role of these alloy additions on Sn self-diffusion along the grain boundaries. This is particularly surprising, since transmission electron microscopy clearly shows segregation of $\mathrm{Pb}$ precipitates at Sn grain boundaries even with only $2 \mathrm{wt} \% \mathrm{~Pb}$ [12].

It was therefore deemed necessary to evaluate the possible role of dopant atoms, such as $\mathrm{Pb}$ and In, on the grain boundary diffusivity of Sn atoms, and therefore on their potential influence on whisker growth rate in Sn coatings. The interatomic interactions leading to localized segregation and any interference with the diffusing species occur at extremely small length and 
time scales and, therefore, cannot be directly accessed by continuum models. For instance, the ability of Sn atoms to segregate from the bulk and diffuse to the interface depends primarily on the interactions between the atoms constituting the interface and the dopant atoms. Therefore, the purpose of this study is to use a molecular dynamics (MD) approach to: (1) validate the tendency for $\mathrm{Pb}$ atoms to segregate at Sn grain boundaries, (2) examine whether similar interactions occur between In atoms and $\mathrm{Sn}$ grain boundaries, and (3) evaluate the effect of $\mathrm{Pb}$ and In solute atoms on grain boundary self-diffusivity of Sn. The objective is to assess whether boundary selfdiffusivity can be sufficiently slowed by dopant segregation to explain the dramatic reduction in Sn whisker growth seen as a result of the additions of $\mathrm{Pb}$ and In.

\section{BACKGROUND}

\subsection{Influence of Solute Atoms on Grain Boundary Self-Diffusivity}

Often, the incorporation of solute atoms, and segregation thereof at grain boundaries, reduces grain boundary self-diffusivity in alloys. Segregation of solute atoms at the grain boundary occurs even at very small solute concentrations (i.e., $\alpha=\mathrm{C}_{\mathrm{gb}} / \mathrm{C}_{\mathrm{v}}>1$, where $\mathrm{C}_{\mathrm{gb}}$ is the grain boundary concentration, and $\mathrm{C}_{\mathrm{v}}$ is the concentration within the volume or grain interior) [27, 28]. Some solute atoms segregate severely $(\alpha>>1)$ whereas some solute atoms for a given solvent metal segregate only weakly $(\alpha>1$ but $\alpha<10)$. The extent of the segregation depends on the rate at which grain boundary energy increases per solute atom, as per the Gibbs adsorption equation $[29,30]$. Empirical evidence suggests that the extent of segregation would be severe if the solute solubility limit is small [30], and is greater at high-angle grain boundaries [29, 30]. Furthermore, it is also observed that the segregation of substitutional solute atoms at grain boundaries increases activation energy and reduce grain boundary diffusivity in many metals [27, 29, 31]. This is also true for ceramics, where misfit strain associated with a large dopant ion 
significantly reduces grain boundary diffusion and can result in drastic reduction of creep rate [32-34].

\subsection{Previous MD work, Sn grain boundary misorientations}

MD simulations [35-37] present fundamental theoretical techniques that can account for atomistic interactions and can hence accurately model diffusion at metallic surfaces[38] and interfaces [39-41]. Recently, MD simulations were conducted on self-diffusivity in various tilt boundaries as well as solute segregation on $\beta$-Sn grain boundary [39, 40]. These studies report that the highest energy boundaries are associated with largest boundary width. In general, the boundary width decreased with addition of solute to Sn, depending on the relative magnitudes of the solute-Sn and Sn-Sn cohesive energies. Although some of this work considered highly nonequilibrium amounts of small solute atoms in interstitial positions [40], generally, segregation of solute at GB appears to reduce GB self-diffusivity significantly [22]. For instance, in a separate MD study, it was shown that atoms either smaller or larger than the solvent reduced GB energy, with the effect being largest for larger atoms [42]. Table 1 shows a summary of the effect of solute atoms on width-scaled grain boundary diffusivity $\left(\delta_{\mathrm{gb}} \mathrm{D}_{\mathrm{gb}}\right)$ or the activation energy for grain boundary diffusion $\left(\mathrm{Q}_{\mathrm{gb}}\right)$ [28, 31, 43-46]. In the majority of cases, $\mathrm{Q}_{\mathrm{gb}}$ increases significantly upon solute addition, whereas $\delta_{\mathrm{gb}} \mathrm{D}_{\mathrm{gb}}$ decreases.

However, the literature lacks a systematic and detailed computational study that addresses the role of additives on the diffusion of $\mathrm{Sn}$ in the vicinity of realistic grain boundaries. In the present study, classical MD simulations were conducted to directly account for interaction of $\mathrm{Pb}$ and In dopant atoms with Sn and determine their role on the diffusion of Sn atoms at grain boundaries. $\mathrm{Pb}$ is widely known as a dopant atom that slows down the growth of Sn whiskers and was therefore selected as a model dopant in the present study. As an alternative to generate $\mathrm{Pb}$ - 
free devices, In has been recently explored and shown to mitigate whisker growth. Therefore, the present study also investigated In as a dopant species.

Table 1: Effect of Solute Atoms on GB Diffusivity/Activation Energy for Diffusion

\begin{tabular}{|c|c|c|c|c|}
\hline Solvent & Solute & at\% solute & Grain boundary diffusivity of solvent atoms & Ref \\
\hline \multirow[t]{2}{*}{$\mathrm{Fe}$} & \multirow[t]{2}{*}{$\mathrm{S}$} & \multirow[t]{2}{*}{$3.5 \times 10^{-7}$} & $\mathrm{Q}_{\mathrm{gb}}($ pure $\mathrm{Fe})=99 \mathrm{~kJ} / \mathrm{mol}$ & \multirow{2}{*}{ [41] } \\
\hline & & & $\mathrm{Q}_{\mathrm{gb}}(\mathrm{Fe} / \mathrm{S})=164 \mathrm{~kJ} / \mathrm{mol}$ & \\
\hline \multirow[t]{2}{*}{$\mathrm{Fe}$} & \multirow[t]{2}{*}{$\mathrm{Sn}$} & \multirow[t]{2}{*}{0.25} & $\delta \mathrm{D}_{\mathrm{gb}}($ pure $\mathrm{Fe})=4 \times 10^{-21} \mathrm{~m}^{3} / \mathrm{s}$ at $681^{\circ} \mathrm{C}$ & \multirow{2}{*}{ [31] } \\
\hline & & & $\delta \mathrm{D}_{\mathrm{gb}}(\mathrm{Fe} / \mathrm{Sn})=2 \times 10^{-21} \mathrm{~m}^{3} / \mathrm{s}$ at $681^{\circ} \mathrm{C}$ & \\
\hline \multirow[t]{2}{*}{$\mathrm{Fe}$} & \multirow[t]{2}{*}{$\mathrm{Sb}$} & \multirow[t]{2}{*}{0.03} & $\delta \mathrm{D}_{\mathrm{gb}}($ pure $\mathrm{Fe})=4.8 \times 10^{-22} \mathrm{~m}^{3} / \mathrm{s}$ at $550^{\circ} \mathrm{C}$ & \multirow[t]{2}{*}{ [42] } \\
\hline & & & $\delta \mathrm{D}_{\mathrm{gb}}(\mathrm{Fe} / \mathrm{Sb})=8 \times 10^{-21} \mathrm{~m}^{3} / \mathrm{s}$ at $550^{\circ} \mathrm{C}$ & \\
\hline \multirow[t]{2}{*}{$\mathrm{Fe}$} & \multirow[t]{2}{*}{$\mathrm{Sb}-\mathrm{Ni}$} & \multirow{2}{*}{$\begin{array}{c}\mathrm{Sb}=0.03 \\
\mathrm{Ni}=1\end{array}$} & $\delta \mathrm{D}_{\mathrm{gb}}($ pure $\mathrm{Fe})=5 \times 10^{-22} \mathrm{~m}^{3} / \mathrm{s}$ at $550^{\circ} \mathrm{C}$ & \multirow[t]{2}{*}{ [42] } \\
\hline & & & $\delta \mathrm{D}_{\mathrm{gb}}(\mathrm{Fe}-\mathrm{Sb} / \mathrm{Ni})=1.4 \times 10^{-21} \mathrm{~m}^{3} / \mathrm{s}$ at $550^{\circ} \mathrm{C}$ & \\
\hline \multirow[t]{2}{*}{$\mathrm{Cu}$} & \multirow[t]{2}{*}{$\mathrm{S}$} & \multirow{2}{*}{$\begin{array}{r}5 \times 10^{-7} \text { vs. } \\
1.5 \times 10^{-6}\end{array}$} & $\delta \mathrm{D}_{\mathrm{gb}}\left(\mathrm{Cu}-5 \times 10^{-7}\right.$ of $\left.\mathrm{S}\right)=2.1 \times 10^{-21} \mathrm{~m}^{3} / \mathrm{s}$ at $445^{\circ} \mathrm{C}$ & \multirow[t]{2}{*}{ [28] } \\
\hline & & & $\delta \mathrm{D}_{\mathrm{gb}}\left(\mathrm{Cu}-1.5 \times 10^{-6}\right.$ of $\left.\mathrm{S}\right)=8.1 \times 10^{-22} \mathrm{~m}^{3} / \mathrm{s}$ at $445^{\circ} \mathrm{C}$ & \\
\hline \multirow[t]{2}{*}{$\mathrm{Cu}$} & \multirow[t]{2}{*}{$\mathrm{Ag}$} & \multirow[t]{2}{*}{0.091} & $\mathrm{Q}_{\mathrm{gb}}($ pure $\mathrm{Cu})=90 \mathrm{~kJ} / \mathrm{mol}$ & \multirow[t]{2}{*}{ [43] } \\
\hline & & & $\mathrm{Q}_{\mathrm{gb}}(\mathrm{Cu} / \mathrm{Ag})=119 \mathrm{~kJ} / \mathrm{mol}$ & \\
\hline $\mathrm{Au}$ & $\mathrm{Ta}$ & 1.2 & $\begin{aligned} \mathrm{Q}_{\mathrm{gb}}(\text { pure } \mathrm{Au})= & 84.9 \mathrm{~kJ} / \mathrm{mol}, \mathrm{Q}_{\mathrm{gb}}(\mathrm{Au} / \mathrm{Ta})= \\
& 121.6 \mathrm{~kJ} / \mathrm{mol}\end{aligned}$ & [44] \\
\hline
\end{tabular}

\section{METHODOLOGY}

The Sn grain boundary was constructed based on an interface bounded by two single crystals of Sn. As a first step, the unit cell of a $\beta$-Sn crystal, which has a body centered tetragonal (bct) structure shown in Figure 1, was generated and single crystals of $\beta$-Sn with orthogonal faces were constructed. Two such single crystals of $\beta$-Sn, each with orthogonal faces and body centered tetragonal (bct) structure, were placed on top of each other to generate a rudimentary grain boundary structure. The $y$-faces of the two crystals form the grain boundary. The $x-y-z$

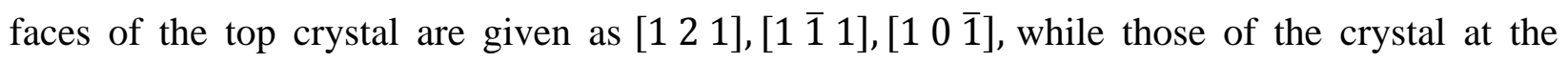
bottom are defined by $\left[\begin{array}{lll}1 & 0 & 0\end{array}\right],\left[\begin{array}{lll}0 & \overline{1} & 0\end{array}\right],\left[\begin{array}{lll}0 & 0 & 1\end{array}\right]$. The choice of this specific interface was guided by 
available electron backscatter diffraction (EBSD) data for Sn grain boundaries immediately below a growing whisker from an electroplated Sn film which showed several such boundaries [47]. It is noted that unlike most previous MD simulations of pure tilt boundaries [40, 42, 48], this widely prevalent boundary type in Sn-platings has a combination of tilt and twist misorientations, and as such, represents a generalized tilt-twist boundary. It is further noted that electroplated Sn coatings typically comprise columnar grains with a fiber-texture, and as such, the grain boundaries have significant twist character, making the choice of the above grain orientations particularly cogent.

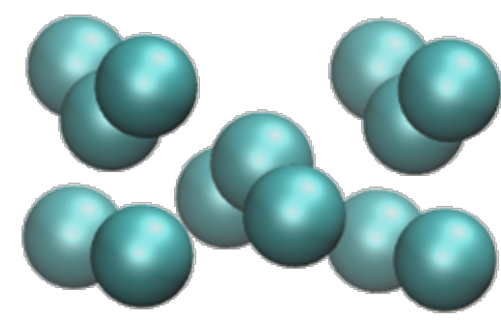

(a)

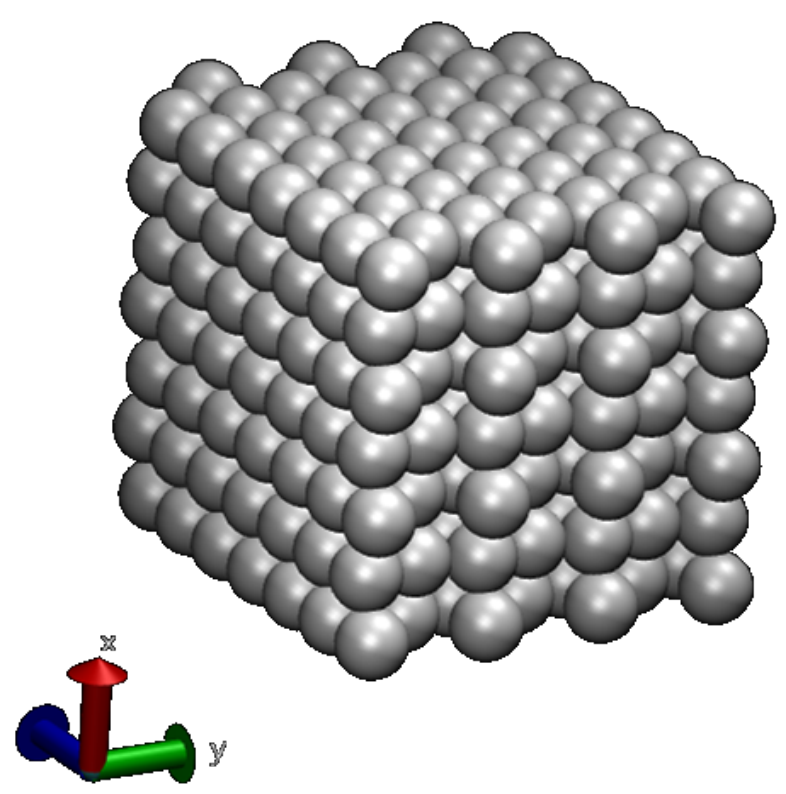

(b)

Figure 1. (a) The body centered tetragonal structure of atoms of $\beta$-Sn crystal is shown. (b) A single crystal with orthogonal [ $\left[\begin{array}{lll}1 & 0 & 0\end{array}\right],\left[\begin{array}{lll}0 & 1 & 0\end{array}\right]$ and [ $\left[\begin{array}{lll}0 & 0 & 1\end{array}\right]$ faces is shown in 3-dimensions.

The size of the comprehensive simulation domain, shown in Figure 2, is $80.9 \AA \times 90.6 \AA \times$ $80.9 \AA$ and comprises 21165 atoms. A static energy minimization, using steepest descent method was first performed at $0 \mathrm{~K}$ such that atoms at the interface can adjust positions to reach energetically favorable state. The grain boundary structure was created following an algorithm 
adopted from Tschopp et al [49, 50]. This was followed by full dynamic equilibration at $400 \mathrm{~K}$ such that the comprehensive system reaches an equilibrated configuration. The Modified Embedded Atom Method (MEAM) potential [51] was employed to describe the interaction potentials between the atoms of $\mathrm{Sn}$ and $\mathrm{Pb}$. In case of $\mathrm{Sn}$ and In, the parameters for In were obtained from recent work of Do et al [52].

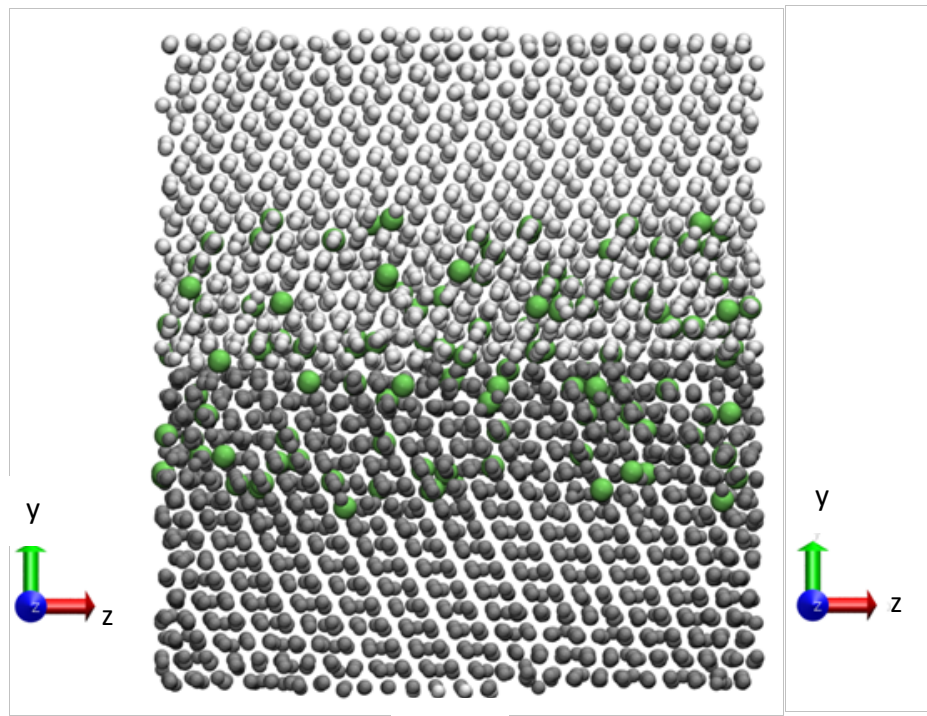

(a)

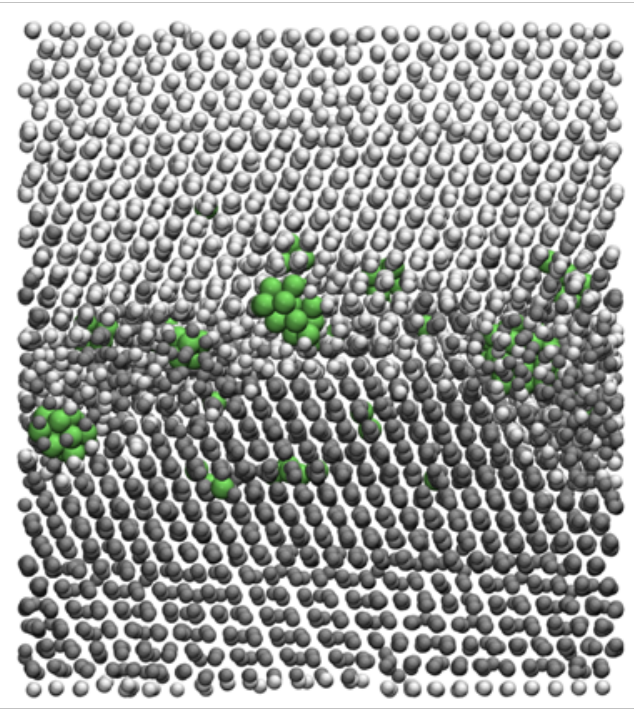

(b)

Figure 2. Snapshots from molecular dynamics simulations showing (a) initial configuration, and (b) configuration after $20 \mathrm{~ns}$ simulation of Sn grain boundaries. The faces of the crystal at the

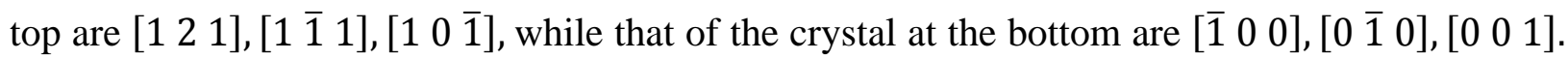

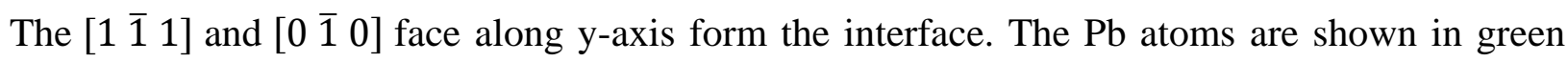
while the Sn atoms of the top and bottom crystals are shown as silver and gray colored atoms respectively. Considerable mixing happens at the interface.

In an effort to access diffusion of $\mathrm{Sn}$ in a computationally reasonable time scale, a relatively high vacancy concentration of $1 \%$ mole fraction was introduced by removing atoms randomly from lattice sites. The systems with pure Sn crystal based grain boundaries were employed as benchmark systems. Additionally, systems with $\mathrm{Pb}$ or In atoms were built in order to study the effect of dopant atoms on diffusion of Sn. These systems were constructed by randomly 
replacing Sn atoms in the body centered tetragonal lattice sites. The mole fraction of the supplied dopant atoms was $4 \%$. Once an equilibrated structure was obtained, the production simulations were run for at least 50 nanoseconds. We used the massively parallelized software LAMMPS [53] developed at Sandia National Laboratory for the MD simulations. The desired temperature of $400 \mathrm{~K}$ was maintained by employing a Nosé-Hoover thermostat [54].

The partial atomic density distribution of In and $\mathrm{Pb}$ atoms with respect to the interface was obtained at various times during the simulation to track the migration of dopants, which were initially randomly dispersed. For this purpose, bins of thickness $2 \AA$, parallel to the interface, were defined and the time-averaged number of dopant atoms was obtained. In an effort to calculate self-diffusivity of Sn atoms along the grain boundary, a $3 \mathrm{~nm}$ thick region was defined symmetrically around the grain boundary. The mean squared displacement of Sn atoms in this region, along the plane of the grain boundary, was obtained as a function of simulation time. Based on Einstein's relation [36, 37], the diffusivity is proportional to the slope of the mean squared displacement in the two dimensions:

$$
\mathrm{D}_{\mathrm{Sn}}=\lim _{\mathrm{t} \rightarrow \infty} \frac{1}{4 \mathrm{Nt}}\left\langle\sum_{\mathrm{j}=1}^{\mathrm{N}}\left[\mathrm{r}_{\mathrm{j}}(\mathrm{t})-\mathrm{r}_{\mathrm{j}}(0)\right]^{2}\right\rangle,
$$

where, $r_{j}(t)$ is the displacement of the atom $j$ during time $t$ in the two dimensions parallel to the interface, $<>$ is the ensemble average, $\mathrm{N}$ is the total number of atoms in the domain, and the quantity in the angular bracket is the sum of squared displacements.

\section{RESULTS}

The goals of the modeling effort in the present study were to construct energetically favorable and experimentally observed grain boundaries comprising $\beta$-Sn faces, to introduce $\mathrm{Pb}$ or In dopant atoms by substituting random crystal sites, study the migration of the dopant atoms 


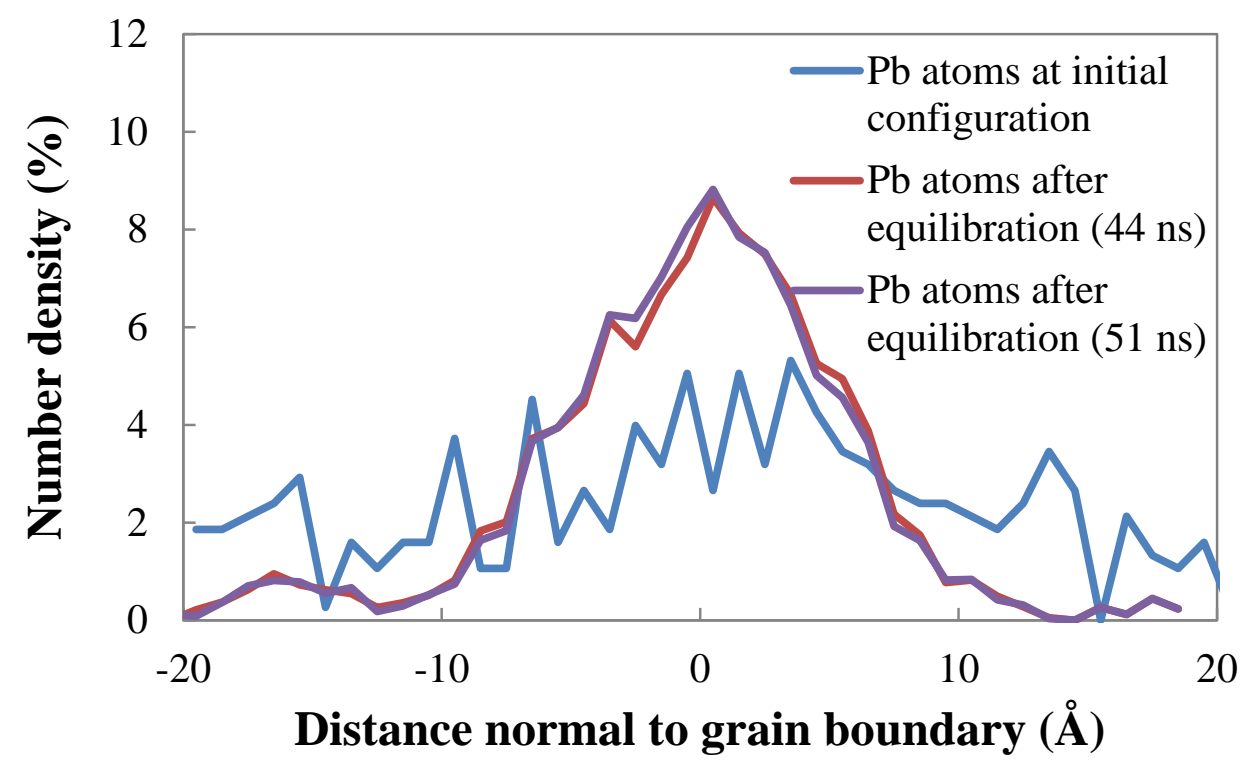

(a)

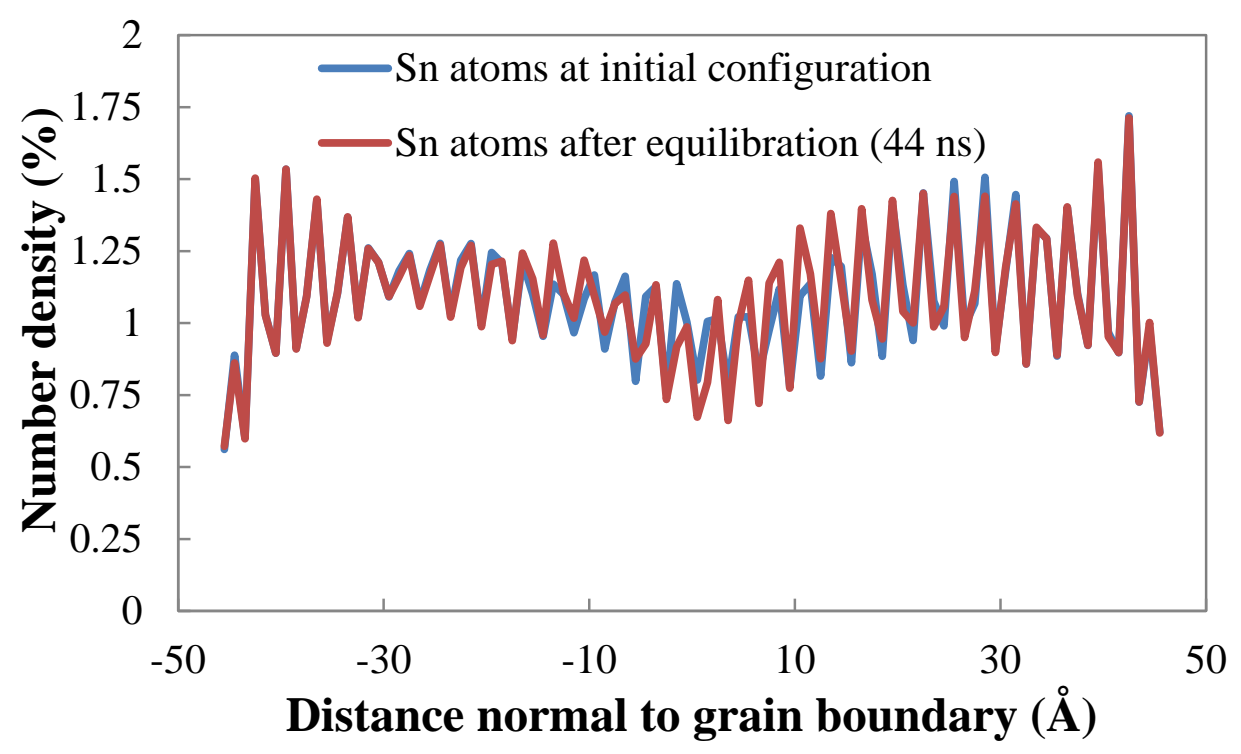

(b)

Figure 3. The number density distribution, expressed as percentage of total atoms of (a) $\mathrm{Pb}$ and (b) Sn, along the direction normal to the grain boundary is shown. The distribution of $\mathrm{Pb}$ atoms corresponding to the initial configuration is discrete and random while that corresponding to the final configuration is more continuous and shows peaks in the vicinity of the grain boundary. For the distribution corresponding to later configurations in the simulation, the number densities are time averaged over several configurations. 
with respect to the location of the grain boundary, and finally, to evaluate the effect of $\mathrm{Pb}$ or $\mathrm{In}$ on the diffusion of Sn atoms in the vicinity of the grain boundary. We began with the hypothesis that reduction of grain boundary self-diffusivity of Sn due to presence of dopant atoms decreases whisker growth rate, and the principal objective was to investigate the validity of this hypothesis.

As a first step in understanding the mechanism of observed whisker inhibition in presence of $\mathrm{Pb}$ dopant atoms, we performed MD simulations to track the time-evolution of the distribution of $\mathrm{Pb}$ atoms relative to the grain boundary. Representative simulation snapshots of the grain boundary right after introduction of $\mathrm{Pb}$ and after $20 \mathrm{~ns}$ of simulation are provided in Figure 2. While Figure 2 (a) shows the initial configuration, where single $\mathrm{Pb}$ atoms are randomly distributed, Figure 2 (b) shows snapshots from the simulations after they had run for $10 \mathrm{~ns}$. Whereas at the beginning the $\mathrm{Pb}$ atoms are placed randomly throughout the domain, with progression of the simulation, the $\mathrm{Pb}$ atoms form small clusters and migrate towards the grain boundary, which is indicated by the segregation of $\mathrm{Pb}$ atoms near the grain boundary. In order to get quantitative insight into the migration of $\mathrm{Pb}$ atoms, the number density of $\mathrm{Pb}$ atoms, expressed as percentage of the total number of $\mathrm{Pb}$ atoms, in the direction normal to the grain boundary (along y-axis in the simulation domain) is shown in Figure 3. These were calculated by defining bins of size $1 \AA$ that comprise slabs along x-z planes parallel to the grain boundary. In Figure 3(a), the distribution of $\mathrm{Pb}$ atoms corresponding to the initial configuration is discrete and fairly random, with alternating peaks and troughs. The number density distributions for the timeevolved configurations were obtained as time-averaged quantities. Well-formed peaks can be seen in the equilibrated system in Figure 3(a). It is also to be noted that the number density distributions of the $\mathrm{Pb}$ atoms do not change significantly between 44 and 51 ns after introduction of $\mathrm{Pb}$, indicating that the system reaches equilibrium configuration at around $44 \mathrm{~ns}$. The density 
distributions of $\mathrm{Pb}$ atoms in the equilibrated systems indicate that the concentration of the $\mathrm{Pb}$ atoms in the immediate vicinity of the grain boundary is a lot greater than that away from it, thus suggesting segregation at the grain boundary. While at the starting configuration the concentration of $\mathrm{Pb}$ is relatively uniform and is $4 \%$ by mole fraction, the final configuration comprises $\mathrm{Pb}$ of around $11.5 \%$ mole fraction within $5 \AA$ on either side of the grain boundary. Since the simulated system evolves through time, the precise location of the grain boundary shifts slightly to reach an energetically favorable configuration. To determine the location of the grain boundary, the distributions of Sn atoms were evaluated at the beginning of the simulation and after equilibration and are shown in Figure 3(b). While the distribution is mostly unchanged far away from the grain boundary, the grain boundary region shows changes indicating shift of the grain boundary towards the positive y-axis. The location of the grain boundary is consistent with the peak of the distribution of $\mathrm{Pb}$ atoms presented in Figure 3(a). The fluctuation in the average atomic number density of $S n$ is rather low at greater than $20 \AA$ from the interface, with regular peaks and troughs corresponding to the crystalline configuration of pure Sn. The slight dip in the average distribution of $\mathrm{Sn}$ atoms near the grain boundary indicates presence of $\mathrm{Pb}$ dopants as well as increased vacancy concentration.

Similar analysis was performed for the systems with In dopant atoms and the results are presented in Figure 4. The distribution in the initial configuration is uniform, indicating randomly distributed In atoms. While qualitatively the distribution after equilibration is similar to that of $\mathrm{Pb}$ and shows segregation near the grain boundary, the peaks occur over a broader range for In than in $\mathrm{Pb}$. The distribution of In atoms indicates that they are spread uniformly in the vicinity of the grain boundary with very low concentration at more than $15 \AA$ from it. While at the starting configuration the concentration of In is relatively uniform at $4 \%$ by mole fraction, 


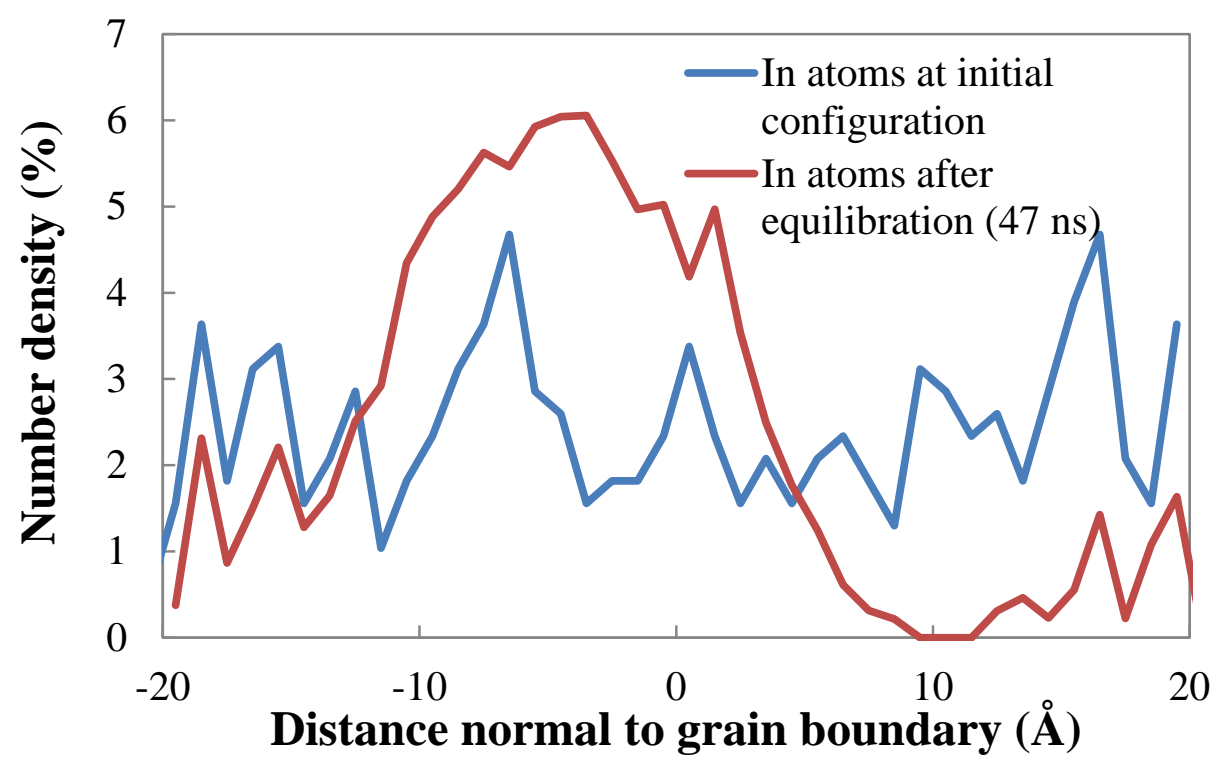

(a)

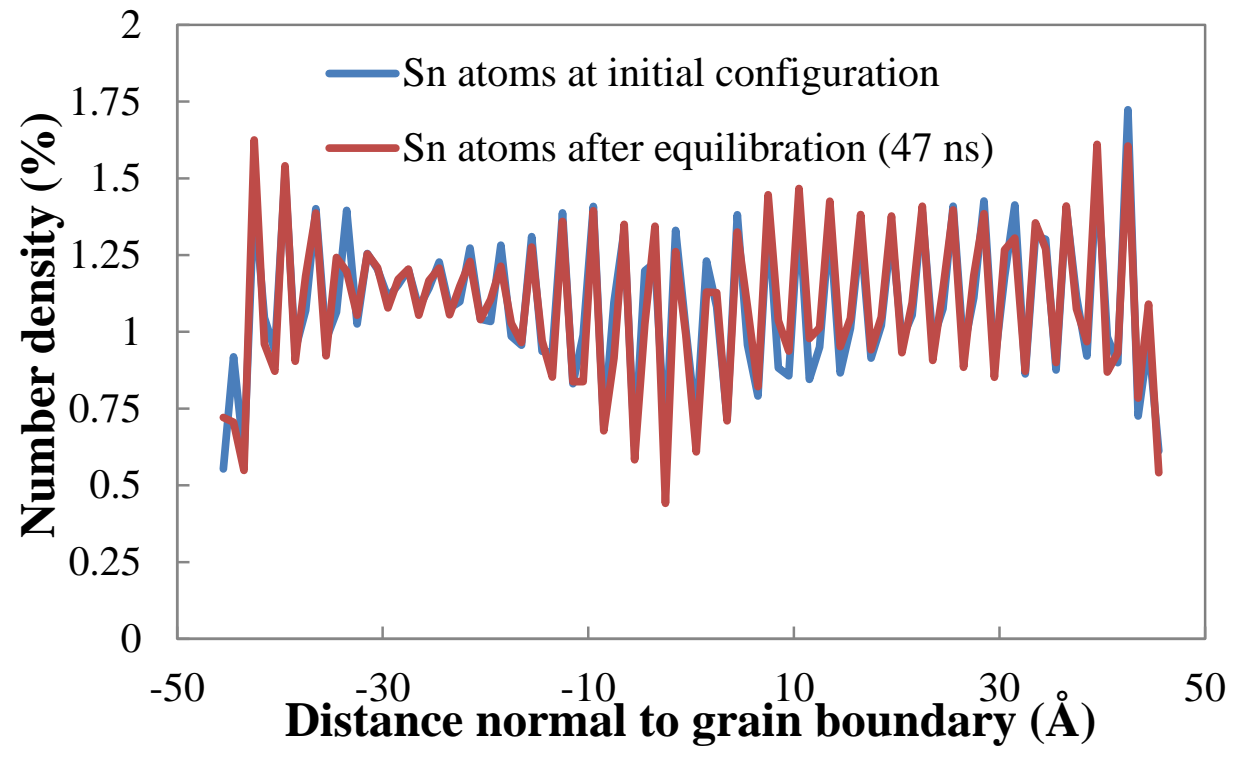

(b)

Figure 4. The number density distribution, expressed as percentage of total atoms of (a) In and (b) Sn, along the direction normal to the grain boundary is shown. The distribution of In atoms corresponding to the initial configuration is discrete and random while that corresponding to the final configuration is more continuous and shows peaks in the vicinity of the grain boundary. For the distribution corresponding to later configurations in the simulation, the number densities are time averaged over several configurations. 
the final configuration comprises In of around $9.6 \%$ mole fraction within $5 \AA$ on either side of the grain boundary. Figure 4(b) shows the density distribution of Sn atoms in In-Sn system for the initial and equilibrated configurations. In this case, the grain boundary shifts slightly in the negative y-direction, which is consistent with the peak in the density of In presented in Figure 4(a). As seen in the Sn-Pb system, the fluctuation in the average atomic number density of $\mathrm{Sn}$ is rather low at greater than $20 \AA$ from the interface, with regular peaks and troughs corresponding to the crystalline configuration of pure Sn.

The rate of increase of the whisker length $h$ with time $t$ (i.e., the whisker growth rate, $\Delta h / \Delta t$ ) may be written as [16]:

$$
\frac{\Delta h}{\Delta t}=\frac{2}{\ln \left(\frac{b}{a}\right)} \frac{\sigma_{o} \Omega s D}{k T a^{2}}
$$

where $D$ is the effective self-diffusivity of Sn through the film, $2 a$ and $2 b$ are the whisker diameter and whisker spacing, respectively, $\Omega$ is the atomic volume of Sn, $\sigma_{o}$ is the equibiaxial plane stress in the film, $k$ is Boltzmann's constant, $T$ is the temperature of whisker growth, and $s$ is the instantaneous whisker-growth step height. It is noted that in electroplated Sn films with columnar grains of diameter around $1 \mu \mathrm{m}$, grain boundary diffusion dominates, and therefore, $D \approx D_{g b}$. As evident from equation 2, the whisker growth rate is directly proportional to the grain boundary diffusivity, and hence, a reduction in $D_{g b}$ is expected to translate directly to a reduction in whisker growth rate. These calculations were performed for systems with pure Sn grain boundary as well as for systems with In and Pb dopant atoms. The results are shown in Figure 5. As a benchmark, the self-diffusion coefficient of Sn atoms at the grain boundary for the control (pure Sn) was calculated for an equilibrated system to be $1.5 \times 10^{-11} \mathrm{~m}^{2} / \mathrm{s}$ at $400 \mathrm{~K}$. As a reference, the diffusion coefficient of Sn away from the interface at the same temperature is $9.8 \times$ 
$10^{-13} \mathrm{~m}^{2} / \mathrm{s}$, which is more than an order of magnitude smaller than that at the grain boundary. The relatively low value of diffusion coefficient occurs as a consequence of the low vacancy concentration in the region away from the grain boundary as seen from the distribution of atoms in Figs. 3(b) and 4(b). As described earlier, $\mathrm{Pb}$ and In dopant atoms were introduced in this equilibrated system and further equilibrated for $\sim 45 \mathrm{~ns}$. The calculated values of self-diffusivity of Sn atoms in the system with $\mathrm{Pb}$ and In were $4.9 \times 10^{-12} \mathrm{~m}^{2} / \mathrm{s}$ and $7.0 \times 10^{-12} \mathrm{~m}^{2} / \mathrm{s}$ respectively, which are significantly lower than the value $1.5 \times 10^{-11} \mathrm{~m}^{2} / \mathrm{s}$ for pure Sn. Indeed, the presence of $\mathrm{Pb}$ and In reduces diffusion coefficient of Sn by factors of approximately 3 and 2, respectively.

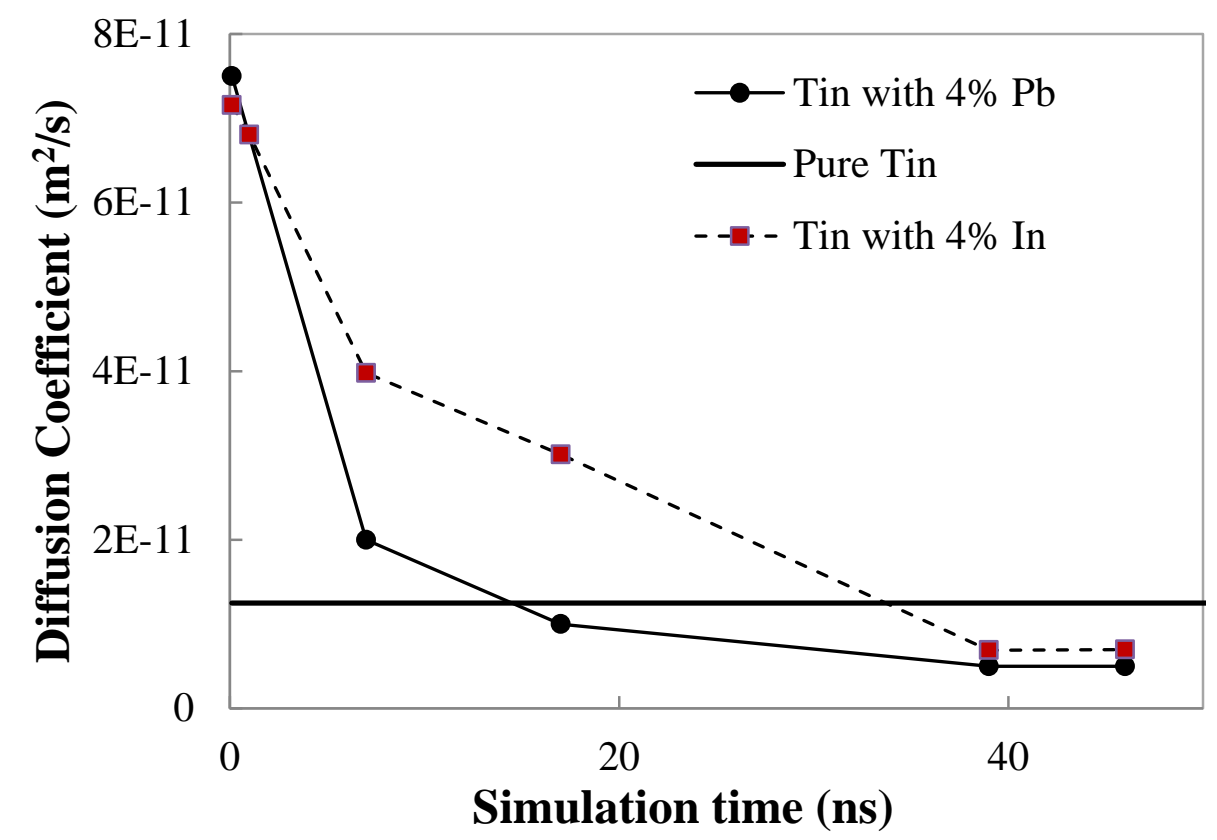

Figure 5. The surface self-diffusion coefficient of Sn atoms in the plane of grain boundary at $400 \mathrm{~K}$ is presented. The diffusion coefficients are calculated as a function of time after the dopant atoms are introduced and the data indicates that they converge after 40ns. The values are compared with that for Sn atoms in a control system without dopants, indicated by a solid black line. The lines joining the data points for systems with $\mathrm{Pb}$ and In do not indicate fitted trends, but serve to guide the eye. 
In order to garner fundamental understanding of the mechanism of reduction in mobility of Sn atoms, we determined the diffusion coefficients of Sn in the system with dopants at various times after the introduction of the dopant atoms. The results are presented in Figure 5. Since the starting configurations for these calculations were far from equilibrium the values of selfdiffusion coefficient only serve as an estimate for systems that are in specific configurations with varying extent of clustering of the dopant atoms near the grain boundary. The plots indicate that the diffusion-coefficients of the Sn atoms are very high, relative to that of Sn atoms in pure Sn grain boundary, at the beginning when the atoms are introduced by substituting $\mathrm{Sn}$ atoms. The high-diffusion coefficient can be attributed to the fact that the dopant atoms are randomly dispersed with minimal clustering and high driving force to form clusters that lead to enhanced mobility. As the systems evolve with time and reach more energetically favorable configuration with greater clustering, the diffusion-coefficients of Sn atoms decrease. The values for systems with both $\mathrm{Pb}$ and In dopants converge after $40 \mathrm{~ns}$ and are lower than that for $\mathrm{Sn}$ atoms in the control. While during intermediate times, the diffusion coefficient of Sn is greater for the system with In dopant, these values are calculated for systems away from equilibrium and hence cannot be directly compared since they are functions of the initial configuration.

To verify our hypothesis that the nature of diffusivity changes due to clustering, we calculated the radial distribution functions (RDF), $g(r)$, for dopant atoms with respect to other dopant atoms following the relation:

$$
g_{a b}(r)=\frac{d_{a b}(r)}{4 \pi r^{2} d r \rho_{a}},
$$

where, $a$ and $b$ are the atom/site types, $\operatorname{dn}_{\mathrm{ab}}(\mathrm{r})$ is the average number of $b$ atoms/sites within a spherical shell of radius $r$ and thickness $d r$ enclosing an $a$ atom/site placed at $r=0$, and $\rho_{\mathrm{a}}$ is the 


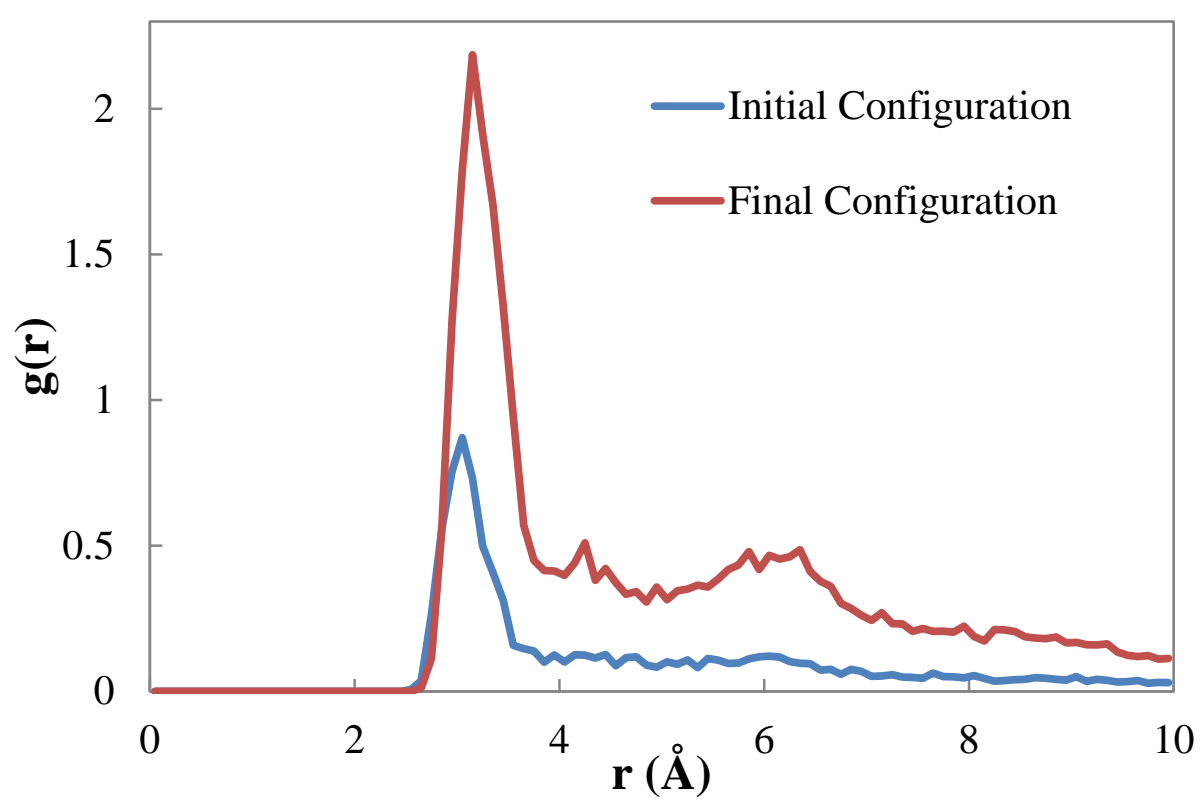

(a)

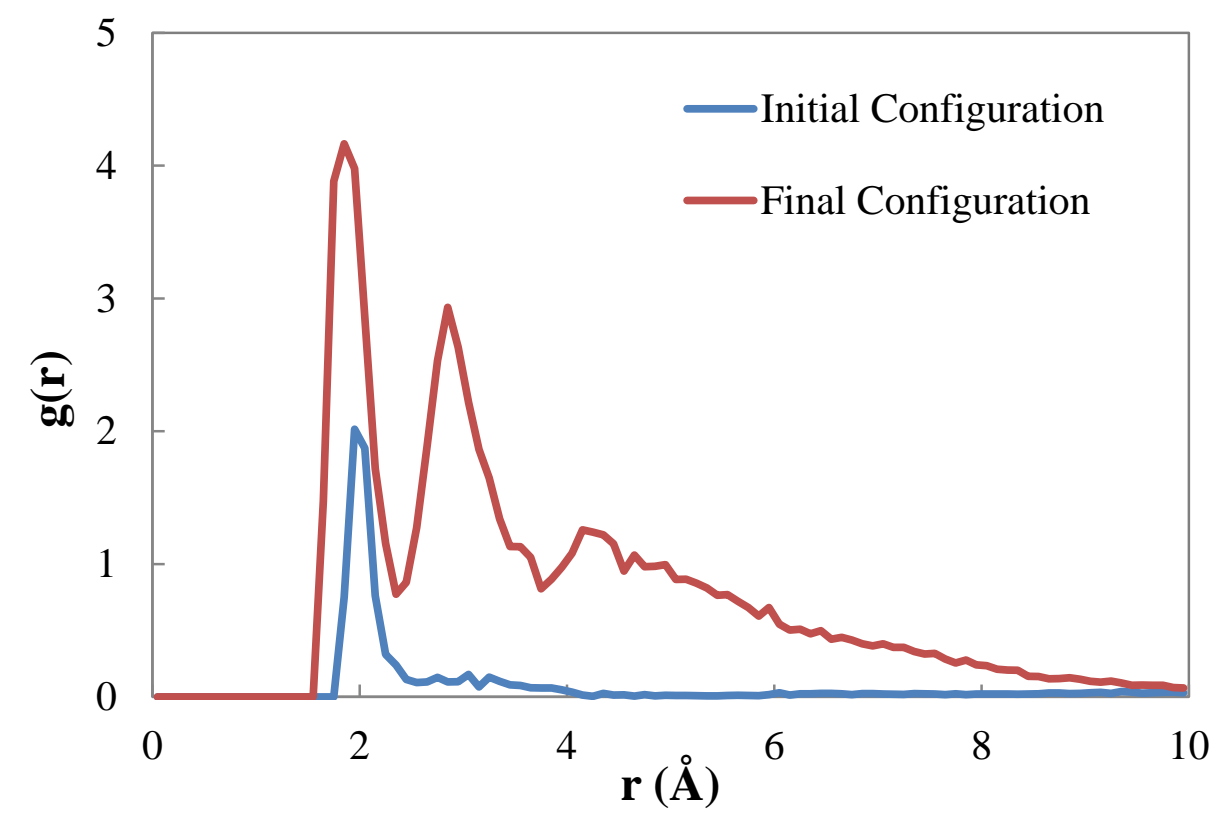

(b)

Figure 6. The radial distribution functions (RDF), g(r), of (a) Pb-Pb and (b) In-In dopant atoms with respect to each other at $400 \mathrm{~K}$ are shown. The RDFs were evaluated at various times from the introduction of dopant atoms and indicate a trend of increasing cluster formation. 
number density of $a$ atom/site. The RDFs for $\mathrm{Pb}$ and In atoms are shown for both initial and equilibrated configurations in Figure 6(a) and 6(b) respectively. In both cases, the peak in RDF becomes more distinct after equilibration is reached, indicating enhanced clustering. However, a second peak is observed for the equilibrated system with In, which indicates the formation of second coordination shells. Since the total concentration of Pb and In dopant atoms are identical, the formation of second coordination shells of In clusters lead us to conclude that larger and fewer dopant clusters occur in case of In compared to that of $\mathrm{Pb}$. The presence of fewer clusters of In can be a possible cause of the slightly greater diffusivity of Sn atoms in systems with In compared to that of $\mathrm{Pb}$.

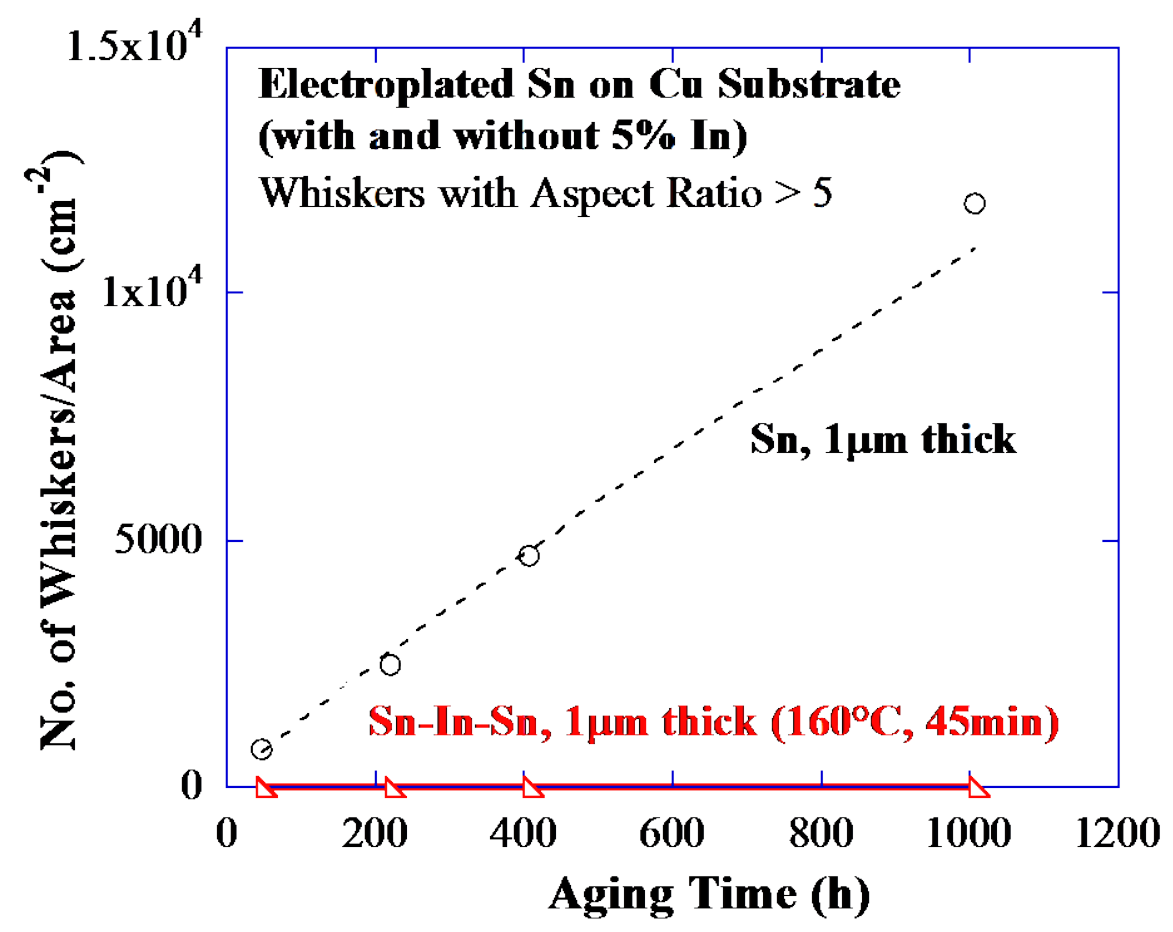

Figure 7: Experimental whisker density data on a $1 \mu \mathrm{m}$ thick layer of electroplated Sn film, and a $1 \mu \mathrm{m}$ thick Sn sandwiching a 50nm thick layer of In, on Cu substrate. The Sn-In-Sn sample was heat-treated at $160^{\circ} \mathrm{C}$ for 45 minutes to incorporate In in the Sn film. [adapted from ref. 25]

\section{DISCUSSION}

In an effort to evaluate the effect of the presence of segregated dopant atoms on the mobility of Sn atoms in the vicinity of the grain boundary, we calculated the width-scaled self-diffusivity of Sn atoms in the systems with and without $\mathrm{Pb}$ and In dopant atoms. We followed an approach 
that has been implemented by Lee et al [48] and Keblinski et al [55], where a modified Einstein relation was used to employed to evaluate diffusivity. The following relation was used:

$$
\delta_{G B} D_{G B}=\frac{\Omega N_{A}}{A} \times \frac{1}{4} \frac{d M S D}{d t},
$$

where, $\delta_{G B}$ is the width of the grain boundary, $N_{A}$ is the number of atoms used for computing the mean-square displacement (MSD), $\Omega$ is the volume of an atom and $D_{G B}$ is the grain boundary diffusivity. The MSD of Sn atoms, in the vicinity of the grain boundary, were obtained after the systems were equilibrated in absence of any externally applied stresses for at least $30 \mathrm{~ns}$. In an effort to validate our model, we calculated the value of $\delta_{G B} D_{G B}$ from Eqn. (3) as $1.69 \times 10^{-20} \mathrm{~m}^{3} / \mathrm{s}$ for the pure Sn system. This value is in the same order of magnitude as that obtained by Lee et al [48] at $400 \mathrm{~K}$, who reported $\delta_{G B} D_{G B}$ value $\sim 1.0 \times 10^{-20} \mathrm{~m}^{3} / \mathrm{s}$. In comparison, the parameter $\delta_{G B} D_{G B}$ for the systems with $\mathrm{Pb}$ and In dopant atoms was evaluated as $5.76 \times 10^{-21} \mathrm{~m}^{3} / \mathrm{s}$ and $8.18 \times 10^{-21} \mathrm{~m}^{3} / \mathrm{s}$ respectively. The calculated values of the width scaled diffusivities from our MD simulations indicate $66 \%$ and 52\% reductions in systems with $\mathrm{Pb}$ and In dopants respectively compared to that of pure Sn, thereby indicating diminished Sn diffusivity in presence of segregated $\mathrm{Pb}$ and In atoms near the grain boundary.

As shown above, the MD results indicate a significant reduction of the grain boundary diffusivity $D_{g b}$, in a $3 \mathrm{~nm}$ thick region situated symmetrically about the boundary, as well as the width-scaled boundary diffusivity, $\delta_{g b} D_{g b}$, when either $\mathrm{Pb}$ or In dopants are added. In both cases, the resultant reduction is $50-67 \%$ relative to the boundary diffusivity in pure Sn. As such, the effects of both $\mathrm{Pb}$ and In on grain boundary diffusivity in $\mathrm{Sn}$ are similar. Since, as shown in equation 2, the whisker growth rate is proportional to effective diffusivity, which is dominated by grain boundary diffusivity at the temperatures of interest, it is to be expected that $\mathrm{Pb}$ or $\mathrm{In}$ 
segregation at Sn grain boundaries would reduce the whisker growth rate by an equivalent amount in doped Sn. However, the experimental data in [25] reveal a much more dramatic effect of doping than that suggested by the simulated effect on diffusivity, as shown in Figure 7, with the growth rate of whiskers of aspect ratios greater than 5 being zero after doping with In. Similar results have been noted on $\mathrm{Sn}$ films doped with $\mathrm{Pb}$ for a long time. This suggests that although the observed reduction in grain boundary diffusivity is clearly one reason that $\mathrm{Pb}$ or $\mathrm{In}$ doped Sn films are less susceptible to whisker-growth, this is not the only source of whiskergrowth reduction. Indeed, it is clear that a mechanism with a stronger effect is responsible for the observed whisker reduction. Although it is beyond the scope of the present work, we hypothesize that the experimentally observed mitigation due to In addition may be caused by a reduction in the driving force for diffusion, as opposed to the rate of diffusion (i.e., diffusivity). This can be achieved by attenuation of the overall stress (equation 2), and hence the stress gradient, in the Sn film, and needs to be investigated.

\section{CONCLUSIONS}

In the present study, we performed MD simulations of grain boundaries comprising pure Sn as well as $\mathrm{Sn}$ with $\mathrm{Pb}$ and In dopant atoms. Our analysis of the MD simulations and calculated atomic densities indicate the segregation of both types of dopant atoms near the grain boundary starting from an initially random distribution. The segregated dopant atoms reduce the diffusion of Sn atoms near the grain boundary by slightly different extents depending on the extent of cluster formation. The RDFs of In-In and $\mathrm{Pb}-\mathrm{Pb}$ atoms indicate the formation of clusters as the randomly distributed dopant atoms dynamically relax to an energetically favorable configuration. Greater coordination is observed in systems with $\mathrm{Pb}$ compared to that of In. The clusters of dopant atoms lead to diminished self-diffusion of Sn atoms near the grain boundaries, as 
evidenced by the lower self-diffusion coefficients in systems with $\mathrm{Pb}$ and In compared to that of pure Sn. Our calculations provide valuable physical insight on the role of $\mathrm{Pb}$ and In dopant atoms on the diffusivity of Sn near grain boundaries. However, the maximum extent of reduction in diffusivity of tin atoms is up to a factor of three, which is small compared to the several orders of magnitude slower growth of whiskers experimentally observed in systems with $\mathrm{Pb}$ or In dopants. Therefore, the results suggest that a different mechanism, such as alteration of the stress state in the Sn film due to incorporation of dopant atoms in the surface oxide layer of Sn, plays a dominant role in the reduction of whisker growth. Still, the results of the current study clearly indicate that grain boundary segregation of certain dopant atoms can substantially reduce grain boundary diffusivity.

\section{Acknowledgements}

The authors gratefully acknowledge financial support of this work by the National Science Foundation (CMMI-1335199/1335491). The authors also acknowledge the contribution of Dr.

Lutz Meinshausen in generating the experimental data in Figure 7.

\section{REFERENCES}

[1] J. A. Brusse, "CARTS 2002 - 22nd Capacitor and Resistor Technology Symposium," March 2002.

[2] H. Leidecker and J. A. Brusse. (2006). Tin whiskers: A history of documented electrical system failures-A briefing, Space Shuttle Program Office; http//nepp.nasa.gov/whisker. Available: http//nepp.nasa.gov/whisker

[3] K. G. Compton, A. Mendizza, and S. M. Arnold, "Filamentary Growths On Metal Surfaces - "Whiskers"," Corrosion, vol. 7, pp. 327-334, 1951.

[4] S. M. Arnold, in Proceedings of the IEEE Electrical Components Conference, 1959, p. 75.

[5] S. M. Arnold, "Repressing the growth of tin whisker," Plating, vol. 53, pp. 96-99, 1966.

[6] J. W. Osenbach, J. M. DeLucca, B. D. Potteiger, A. Amin, and F. A. Baiocchi, "Snwhiskers: truths and myths," Journal of Materials Science: Materials in Electronics, vol. 18, pp. 283-305, 2006.

[7] J. Cheng, P. T. Vianco, B. Zhang, and J. C. M. Li, "Nucleation and growth of tin whiskers," Applied Physics Letters, vol. 98, p. 241910, 2011. 
[8] S. M. Miller, U. Sahaym, and M. G. Norton, "Effect of Substrate Composition on Sn Whisker Growth in Pure Sn Films," Metallurgical and Materials Transactions a-Physical Metallurgy and Materials Science, vol. 41A, pp. 3386-3395, Dec 2010.

[9] I. Dutta, M. Burkhard, S. Kuwano, T. Fujita, and M. W. Chen, "Correlation between surface whisker growth and interfacial precipitation in aluminum thin films on silicon substrates," Journal of Materials Science, vol. 45, pp. 3367-3374, 2010.

[10] M. Sobiech, U. Welzel, E. J. Mittemeijer, W. Huegel, and A. Seekamp, "Driving force for Sn whisker growth in the system Cu-Sn," Applied Physics Letters, vol. 93, Jul 72008.

[11] K. Zeng and K. N. Tu, "Six cases of reliability study of Pb-free solder joints in electronic packaging technology," Materials Science \& Engineering R-Reports, vol. 38, pp. 55-105, Jun 142002.

[12] W. J. Boettinger, C. E. Johnson, L. A. Bendersky, K. W. Moon, M. E. Williams, and G. R. Stafford, "Whisker and hillock formation on Sn, Sn-Cu and Sn-Pb electrodeposits," Acta Materialia, vol. 53, pp. 5033-5050, Nov 2005.

[13] M. Sobiech, J. Teufel, U. Welzel, E. J. Mittemeijer, and W. Huegel, "Stress Relaxation Mechanisms of Sn and SnPb Coatings Electrodeposited on Cu: Avoidance of Whiskering," Journal of Electronic Materials, vol. 40, pp. 2300-2313, Nov 2011.

[14] J. P. Winterstein and M. G. Norton, "The influence of porosity on whisker growth in electroplated tin films," Journal of Materials Research, vol. 21, pp. 2971-2974, Dec 2006.

[15] T. A. Woodrow, "Tracer diffusion in whisker prone Sn platings," in Proceedings of SMTA International Conference, 2006.

[16] K. N. Tu, "Irreversible processes of spontaneous whisker growth in bimetallic Cu-Sn thinfilm reactions," Phys. Rev. B, vol. 49, pp. 2030-2034, 1994.

[17] K. N. Tu and J. C. M. Li, "Spontaneous whisker growth on lead-free solder finishes," Mater. Sci. Eng. A, vol. 409, pp. 131-139, 2005.

[18] K. W. Moon, C. E. Johnson, M. E. Williams, O. Kongstein, G. R. Stafford, C. A. Handwerker, et al., "Observed correlation of Sn oxide film to Sn whisker growth in $\mathrm{Sn}-\mathrm{Cu}$ electrodeposit for Pb-free solders," Journal of Electronic Materials, vol. 34, pp. L31-L33, Sep 2005.

[19] E. Chason, N. Jadhav, W. L. Chan, L. Reinbold, and K. S. Kumar, "Whisker formation in Sn and Pb-Sn coatings: Role of intermetallic growth, stress evolution, and plastic deformation processes," Applied Physics Letters, vol. 92, Apr 282008.

[20] H. P. Howard, J. Cheng, P. T. Vianco, and J. C. M. Li, "Interface flow mechanism for tin whisker growth," Acta Materialia, vol. 59, pp. 1957-1963, Mar 2011.

[21] N. Jadhav, J. Wasserman, F. Pei, and E. Chason, "Stress Relaxation in Sn-Based Films: Effects of Pb Alloying, Grain Size, and Microstructure," Journal of Electronic Materials, vol. 41, pp. 588-595, Mar 2012.

[22] P. Sarobol, A. E. Pedigo, P. Su, J. E. Blendell, and C. A. Handwerker, "Defect Morphology and Texture in Sn, Sn-Cu, and Sn-Cu-Pb Electroplated Films," Ieee Transactions on Electronics Packaging Manufacturing, vol. 33, pp. 159-164, Jul 2010.

[23] H. Leidecker and J. S. Kadesch, "Effects of Uralane Conformal Coating on Tin Whisker Growth," in Proceedings of the 37th IMAPS Nordic Annual Conference, 2000, pp. 108-116.

[24] M. Osterman. Mitigation Strategies for Tin Whiskers; Available: http://www.calce.umd.edu/lead-free/tin-whiskers/TINWHISKERMITIGATION.pdf 
[25] L. Meinshausen, S. Bhassyvasantha, B. S. Majumdar, and I. Dutta, "Influence of Indium Addition on Whisker Mitigation in Electroplated Tin Coatings on Copper Substrates," Journal of Electronic Materials, vol. 45, pp. 791-801, Jan 2016.

[26] L. M. B. Meinshausen, S.Dutta, I.Majumdar, B., "Mitigation of tin whisker growth by dopant addition," in ASME InterPACK/ICNMM 2015, San Francisco, 2015.

[27] H. Gleiter and B. Chalmers, "Grain boundary diffusion," Prog. Mater. Sci., vol. 72, pp. 4376, 1972.

[28] T. Surholt, C. Minkwitz, and C. Herzig, "Solute diffusion and segregation in grain boundaries of silver and copper," Defect and Diffusion Forum, vol. 156, pp. 59-74, 1998.

[29] H. Gleiter and B. Chalmers, "Grain boundary segregation," Prog. Mater. Sci., vol. 72, pp. 77-112, 1972.

[30] M. P. Seah and E.D.Hondros, "Grain Boundary Segregation," Proc. R. Soc. Lond., vol. A335, pp. 191-212, 1973.

[31] J. Bernardini, P. Gas, E. D. Hondros, and M. P. Seah, "The role of solute segregation in grain-boundary diffusion," Proceedings of the Royal Society of London Series aMathematical Physical and Engineering Sciences, vol. 379, pp. 159-178, 19821982.

[32] J. Cho, M. P. Harmer, J. M. Rickman, and H. M. Chan, "Modeling of grain boundary segregation behavior in aluminum oxide," JACerS, vol. 83, pp. 344-352, 2000.

[33] J. Cho, M. P. Harmer, J. M. Rickman, and A. M. Thomson, "Effect of Yttrium and Lanthanum on the tensile creep behavior of aluminum oxide," JACerS, vol. 80, pp. 10101017, 1997.

[34] J. D. French, J. Zhao, M. P. Harmer, and G. A. Miller, "Creep of duplex microstructures," JACerS, vol. 77, pp. 2857-64, 1994.

[35] M. P. Allen, and Tildesley, D.J., Computer Simulation of Liquids: Clarendon Press, Oxford, 1987.

[36] D. J. Evans and G. P. Morris, Statistical Mechanics of Nonequilibrium Liquids. London: Academic, 1990.

[37] J. M. Haile, Molecular Dynamics Simulation: Elementary Methods. New York: Wiley, 1992.

[38] M. S. Sellers, A. J. Schultz, C. Basaran, and D. A. Kofke, "Atomistic modeling of beta-Sn surface energies and adatom diffusivity," Applied Surface Science, vol. 256, pp. 4402-4407, Apr 2010.

[39] M. S. Sellers, A. J. Schultz, C. Basaran, and D. A. Kofke, "beta-Sn grain-boundary structure and self-diffusivity via molecular dynamics simulations," Physical Review B, vol. 81, Apr 1 2010.

[40] M. S. Sellers, A. J. Schultz, C. Basaran, and D. A. Kofke, "Effect of Cu and Ag solute segregation on beta Sn grain boundary diffusivity," Journal of Applied Physics, vol. 110, Jul 12011.

[41] P. C. Millett, R. P. Selvam, and A. Saxena, "Improving grain boundary sliding resistance with segregated dopants," Materials Science and Engineering a-Structural Materials Properties Microstructure and Processing, vol. 431, pp. 92-99, Sep 2006.

[42] P. C. Millett, R. P. Selvan, S. Bansal, and A. Saxena, "Atomistic simulation of grain boundary energetics - Effects of dopants," Acta Materialia, vol. 53, pp. 3671-3678, Aug 2005. 
[43] H. Hansel, L. Stratmann, H. Keller, and H. J. Grabke, "Effects of the grain-boundary segregants $\mathrm{p}, \mathrm{s}, \mathrm{c}$ and $\mathrm{n}$ on the grain-boundary self-diffusivity in alpha-iron," Acta Metallurgica, vol. 33, pp. 659-665, 19851985.

[44] P. Gas and J. Bernardini, "Equilibrium intergranular segregation and diffusion in Ag \$\$n (0-6\%) alloys," Surface Science, vol. 72, pp. 365-378, 3/2/ 1978.

[45] J. Bernardini, Z. Tökei, and D. L. Beke, "Effect of segregation on the shape of grain boundary diffusion profiles Experimental study of the $\mathrm{Cu}[\mathrm{sbnd}] \mathrm{Ag}$ system," Philosophical Magazine A, vol. 73, pp. 237-247, 1996/01/01 1996.

[46] D. Gupta and R. Rosenberg, "Effect of a solute addition (Ta) on low temperature selfdiffusion processes in gold," Thin Solid Films, vol. 25, pp. 171-180, 1// 1975.

[47] D. P. Field, "Private Communication," ed. WSU, 2014.

[48] Y. Lee and C. Basaran, "Effect of Ni solute on grain boundary diffusivity and structure of beta Sn," Computational Materials Science, vol. 92, pp. 1-7, Sep 2014.

[49] M. A. Tschopp and D. L. McDowell, "Asymmetric tilt grain boundary structure and energy in copper and aluminium," Philosophical Magazine, vol. 87, pp. 3871-3892, 20072007.

[50] M. A. Tschopp and D. L. McDowell, "Structures and energies of Sigma 3 asymmetric tilt grain boundaries in copper and aluminium," Philosophical Magazine, vol. 87, pp. 31473173, 20072007.

[51] M. I. Baskes, "Modified embedded-atom potentials for cubic materials and impurities," Physical Review B, vol. 46, pp. 2727-2742, Aug 11992.

[52] E. C. Do, Y.-H. Shin, and B.-J. Lee, "A modified embedded-atom method interatomic potential for indium," Calphad-Computer Coupling of Phase Diagrams and Thermochemistry, vol. 32, pp. 82-88, Mar 2008.

[53] S. Plimpton, "Fast parallel algorithms for short-range molecular-dynamics," Journal of Computational Physics, vol. 117, pp. 1-19, Mar 11995.

[54] D. J. Evans and B. L. Holian, "The Nose--Hoover thermostat," The Journal of Chemical Physics, vol. 83, pp. 4069-4074, 1985.

[55] P. Keblinski, D. Wolf, S. R. Phillpot, and H. Gleiter, "Self-diffusion in high-angle fcc metal grain boundaries by molecular dynamics simulation," Philosophical Magazine a-Physics of Condensed Matter Structure Defects and Mechanical Properties, vol. 79, pp. 2735-2761, Nov 1999. 